\title{
Research on Localization of Serpentine Tube High Pressure Heater
}

\author{
Xuchen Zhu ${ }^{1}$, Yannan $\mathrm{Du}^{1,2^{*}}$, Bin Ren ${ }^{1,2}$, Xiaoying Tang ${ }^{1,2}$ \\ ${ }^{1}$ Shanghai Institute of Special Equipment Inspection and Technical Research, Putuo District, Shanghai, 200062, China \\ ${ }^{2}$ National Heat Exchanger Product Quality Inspection Center, Jinshan District, Shanghai, 201518, China
}

\begin{abstract}
It could be seen that the ultra supercritical reheating is a high-end technology in the field of power equipment manufacturing, which represents the strength and design level of national major equipment manufacturing industry. Based on the development of key components technology of millions of secondary reheat units, solving the design and manufacturing problems of serpentine high-pressure heater, optimizing the heat exchange efficiency of serpentine high-pressure heater, and improving the operation reliability, will help to promote the development process of China's high-end power equipment, and provide important technical support for the quality supervision and management of serpentine high-pressure heater.
\end{abstract}

\section{Introduction}

Manufacturing industry is the main body of the national economy, is the foundation of building a country, the instrument of rejuvenating the country, and the foundation of strengthening the country. High-end power equipment is the key field of China's manufacturing 2025. With the in-depth development of world energy and the improvement of market requirements for environmental protection, coal-fired power generation equipment has gradually developed to the direction of high parameters, large capacity, low heat consumption and environmental protection.Under this development trend, Siemens, Alstom, Ge, Mitsubishi, Hitachi and three major Chinese electric companies (Shanghai Electric, Dongfang Electric and Harbin Electric) have successively developed and put into operation high-efficiency supercritical units and ultra supercritical units.The world's first million class secondary reheat unit independently developed by Shanghai Electric Co., Ltd. (main steam parameters are $31 \mathrm{mpa}, 600{ }^{\circ} \mathrm{C}$, the temperature of primary and secondary reheat steam reaches $610^{\circ} \mathrm{C}$ ) was put into operation in Taizhou Power Plant, Jiangsu Province. The coal consumption of the unit reaches $256.8 \mathrm{~g} / \mathrm{kwh}$ and the power generation efficiency reaches $47.82 \%$, representing the high level of coal-fired units.Subsequently, the steam parameters of the million class secondary reheat unit put into operation by Shanghai Electric in Shandong Laiwu power plant increased the steam parameters (the main steam parameters were $31 \mathrm{mpa}, 600^{\circ} \mathrm{C}$, the temperature of the primary and secondary reheat steam reached $620^{\circ} \mathrm{C}$ ), and the corresponding coal consumption and power generation efficiency further increased. Laiwu secondary reheat unit represents the highest level of coal-fired generating units today.

\section{High Pressure Heater}

High pressure heater is an important auxiliary equipment to improve the thermal economy, and is an important part of the million class secondary reheat unit. It is one of the difficult problems to equip and develop the high pressure heater suitable for ultra-high parameter steam.Compared with the first reheat, the design pressure at the tube side of the high pressure heater is increased from $39 \mathrm{MPa}$ to $44 \mathrm{MPa}$, the maximum shell side pressure is increased from 9.4 $\mathrm{MPa}$ to $13.3 \mathrm{MPa}$, the design temperature of the shell side of the front steam cooler with the highest temperature is increased from 490 to $565{ }^{\circ} \mathrm{C}$, and the design temperature of the top management side is increased from 350 to $360{ }^{\circ} \mathrm{C}$. At present, the configuration of high-pressure heater system mainly includes double row and single row high-pressure heater system. The types of high-pressure heater include U-tube high-pressure heater and serpentine high-pressure heater. If single row U-tube high-pressure heater is used in million class secondary reheat unit, the thickness of tube sheet will exceed $800 \mathrm{~mm}$ if $20 \mathrm{MnMo}$ or equivalent material is used, which will exceed the requirement of $700 \mathrm{~mm}$ maximum nominal thickness of $20 \mathrm{MnMo}$ steel specified in GB 150.2 "allowable stress of carbon steel and low alloy steel forgings". There is no basis for the allowable stress value. At the same time, the temperature difference stress of thick tubesheet is large during operation, which has safety risk, and brings difficulties to machining accuracy, manufacturing cycle and quality control.Although the tube sheet thickness can be optimized about $10 \%$ by using the elastic-plastic analysis design method, it can not meet the increasing demand of 
the unit capacity.The biggest difference between serpentine type high-pressure heater and U-tube highpressure heater is that the inlet header replaces the inlet chamber and tube sheet of U-tube high-pressure heater, and its thickness is about one tenth of the thickness of the tube sheet.Moreover, the serpentine high-pressure heater has better thermal shock resistance, higher temperature rise speed limit and more off design operation times.Statistics show that more than $60 \%$ of large capacity units in foreign countries adopt serpentine header type high pressure heater, and the leakage rate is far lower than that of U-tube high-pressure heater. The continuous and stable operation ability is strong, and the maintenance and repair are difficult. However, the core technology of serpentine high-pressure heater has not been mastered in China, and the key parts need to be imported, which has the disadvantages of high price and long procurement cycle. Compared with U-tube, serpentine high-pressure heater has large initial investment and long production cycle. Compared with U-tube, serpentine high-pressure heater has large diameter, large wall thickness and large thermal resistance. The submerged cooling section has large invalid heat exchange area, large total heat exchange area and relatively low heat exchange efficiency. In addition, the standard lags behind, so the application of serpentine high-pressure heater in China is less. With the deepening of China's supply side reform and the development of high-end power equipment for higher parameters, serpentine high-pressure heater will become the mainstream of future development. The difficulties are as follows: there is no precedent and experience in the application of serpentine high pressure heater in million MW secondary reheat unit at home and abroad.Therefore, the research on the design and manufacturing technology of serpentine high-pressure heater is of great significance for forming the design standard with independent intellectual property rights and improving the manufacturing level of high-end power equipment in China.

\section{Serpentine High Pressure Heater}

Improving the initial parameters and reducing the final parameters of thermal cycle has become an effective means to improve the generating efficiency of steam turbine generator units[1]。At present, Europe and Japan are studying and developing a new generation of high efficiency ultra supercritical power generation technology with higher parameters of 700 (C level).However, the technology is still some time away from commercial application[2]。 The results show that the generation efficiency of the unit can also be improved by increasing the number of reheating when the initial and final parameters are fixed[3]。 For example, the 10 stage regenerative system can effectively improve the unit's wide load economy.The general layout of 10 stage regenerative system is 4 high pressure heaters, 1 Deaerator and 5 low pressure heaters. By adopting 10 stage regenerative system, the rated feed water temperature of the unit can reach between 310 to $330^{\circ} \mathrm{C}$, which is $10{ }^{\circ} \mathrm{C} \sim 30{ }^{\circ} \mathrm{C}$ higher than that of 9stage regenerative system[4]. High pressure heater is an important auxiliary equipment to improve the thermal economy of nuclear power and thermal power plants. The initial parameters of million level secondary reheat are higher than that of primary reheat. The design pressure of high pressure heater tube side is increased from $39 \mathrm{MPa}$ to $44 \mathrm{MPa}$, the maximum shell side pressure is increased from 9.4 MPa to $13.3 \mathrm{MPa}$, and the shell side design temperature of the highest temperature pre steam cooler is increased from 490 to $565^{\circ} \mathrm{C}$, the maximum tube side design temperature increased from 350 to $360{ }^{\circ} \mathrm{C}$. The configuration of high pressure heater system of $1000 \mathrm{MW}$ secondary reheat ultra supercritical unit mainly includes double row and single row high pressure heater system[5-8]The types of high-pressure heaters include U-tube high-pressure heaters and serpentine type high-pressure heaters, as shown in Figure.1 and Figure.2 [3]。 The U-tube high-pressure heater is mainly composed of water chamber, water chamber partition plate, tube bundle, shell, fixed support and sliding support. Taking $1000 \mathrm{MW}$ secondary reheat unit as an example, single row U-tube high-pressure heater is adopted, and the tube sheet is made of $20 \mathrm{MnMo}$ or equivalent material, and its thickness will exceed $800 \mathrm{~mm}$, exceeding the requirement of maximum nominal thickness of $20 \mathrm{MnMo}$ steel $700 \mathrm{~mm}$ in Table 9 allowable stress of carbon steel and low alloy steel forgings in Table 9 of GB 150.2. The allowable stress value is not based on.In foreign countries, considering the risk of thermal fatigue cracking and design life, when the pressure exceeds $35 \mathrm{MPa}$, U-tube high-pressure heater is not recommended, but serpentine tube high-pressure heater is used[9]. Although the thickness of tubesheet can be optimized about $10 \%$ by using elastic-plastic analysis and design method, it can not meet the urgent needs of unit upgrading. The serpentine high-pressure heater is mainly composed of inlet and outlet chamber, tube bundle (serpentine, short connector, etc.), shell, fixed support and sliding support.The biggest difference between the serpentine high-pressure heater and the Utube is that the inlet header replaces the inlet chamber and tube sheet of the U-tube high-pressure heater, and its thickness is about one tenth of the thickness of the tube sheet, which has obvious advantages in high capacity and high parameter conditions. 


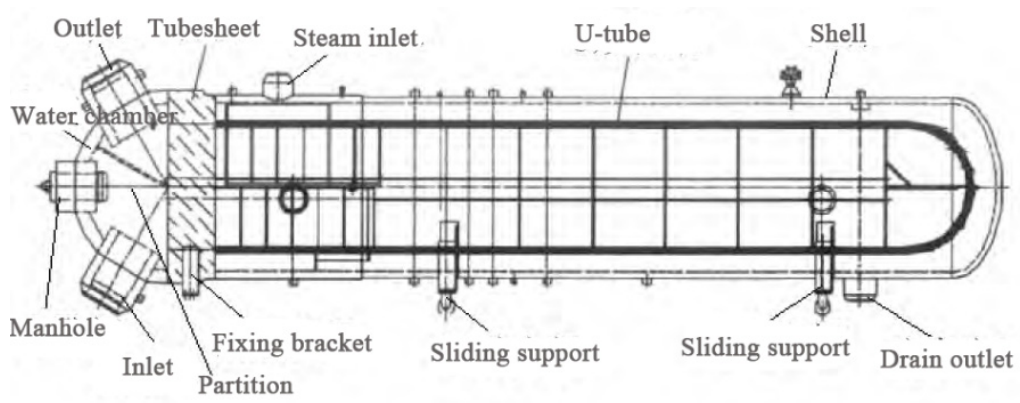

Figure 1. Structure of U-tube high pressure heater ${ }^{[3]}$

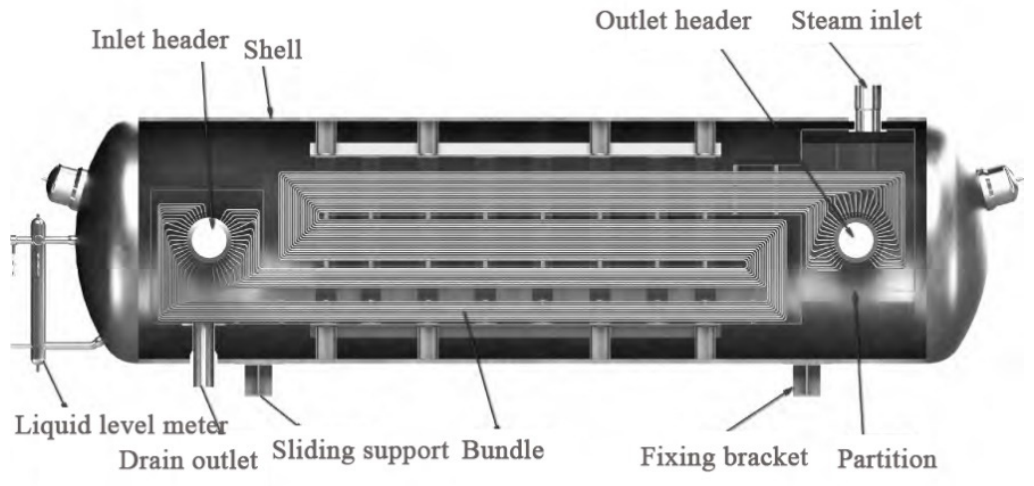

Figure 2. Structure of serpentine high pressure heater ${ }^{[3]}$
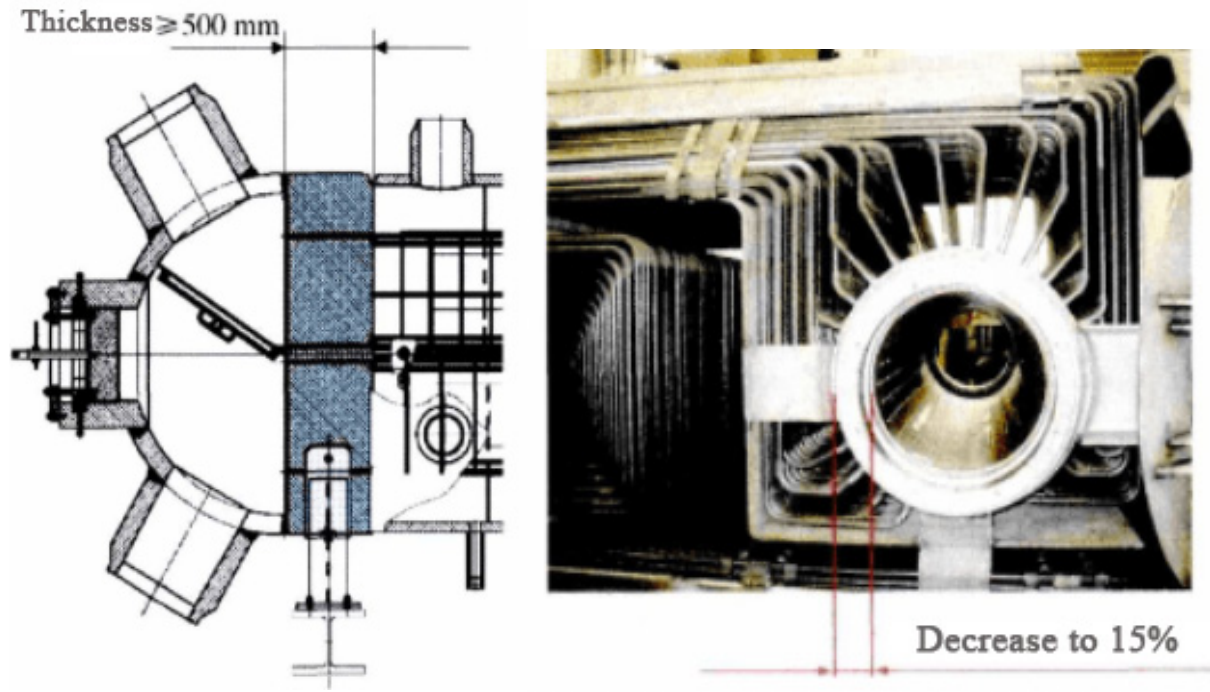

Figure 3. Comparison of internal structure between serpentine and U-tube HP heaters ${ }^{[9]}$

The coiled tube header type high-pressure heater has been put into operation since 1935, and has a history of 80 years. More than 1200 sets of serpentine highpressure heaters have been put into operation. More than $60 \%$ of the large capacity units in foreign countries have adopted serpentine header type high-pressure heaters. Moreover, the tube sheet and U-tube of the U-tube highpressure heater are connected by fillet weld and expansion joint, and helium leak detection is usually used. When the unit starts and stops frequently and the thermal shock operation occurs, the pipe orifice leakage is easy to occur.The serpentine tube type high-pressure heater is connected with the serpentine pipe through the short joint on the header, and the welding seam is $100 \%$ radiographed to ensure the welding quality.The plugging of U-tube high-pressure heater requires people to enter the water chamber for operation; the snakelike highpressure heater plugging pipe is that the machine arm extends into the header, and the personnel operate outside the high-pressure heater, so the working environment is good.The serpentine high-pressure heater can successfully block a single pipe. There are manways in front of and behind the header, so the maintenance is simpler than that of the U-tube heater.In the past 40 years, less than 30 tubes have been damaged, which is far lower than that of U-tube heat exchanger, with strong stability.For the double row high-pressure heater used in million class secondary reheat unit, because its capacity is still within the critical value range allowed by the 
design of U-tube high-pressure heater, the U-tube highpressure heater is still the main one in China.

The comparison between serpentine high-pressure heater and U-tube high-pressure heater is shown in Table 1. It can be seen from the table that there are some shortcomings in the serpentine high-pressure heater. Compared with the U-tube, the serpentine high-pressure heater has large diameter, thick wall and large thermal resistance. The submerged cooling section has large ineffective heat exchange area, large total heat exchange area and relatively low heat exchange efficiency. In order to meet the requirements of heat exchange efficiency, more heat exchange tubes should be arranged to meet the requirements, At the same time, due to the key technology in foreign countries, the number of domestic qualified suppliers is small, the need to import, the existence of high price and long procurement cycle and other shortcomings, seriously restricting the development and application of serpentine high-pressure heater, therefore, it is very important to carry out technical research on the manufacturing process of serpentine high-pressure heater.

Table 1. Comparison of parameters and performance of serpentine and U-tube high pressure heaters

\begin{tabular}{|c|c|c|}
\hline Entry name & U-tube & Serpentine tube \\
\hline $\begin{array}{l}\text { Thermal stress } \\
\text { adaptability }\end{array}$ & $\begin{array}{l}\text { Due to the thick tubesheet, the thermal stress at } \\
\text { the joint of tubesheet and shell is concentrated, } \\
\text { and the possibility of leakage is large }\end{array}$ & Good adaptability \\
\hline $\begin{array}{l}\text { Temperature rise rate } \\
\text { limit }\left({ }^{\circ} \mathrm{C} \cdot \min x^{-1}\right)\end{array}$ & $5 \sim 10$ & $>25$ \\
\hline Drilling difficulty & $\begin{array}{l}\text { The thickness of tubesheet is large and difficult, } \\
\text { so it needs special technology and equipment }\end{array}$ & The thickness of header is small and drilling is easy \\
\hline Pipe to tubesheet weld & $\begin{array}{c}\text { Poor stress, easy to appear defects, only Pt } \\
\text { penetration inspection }\end{array}$ & $\begin{array}{l}\text { The stress condition is excellent, it is not easy to } \\
\text { appear defects, and can be inspected by RT ray. }\end{array}$ \\
\hline Heat exchange tube & $\begin{array}{l}\text { The U-shaped tube has smaller diameter, thinner } \\
\text { wall thickness and smaller thermal resistance. } \\
\text { The siphon cooling section is adopted, and the } \\
\text { total heat exchange area is small. }\end{array}$ & $\begin{array}{l}\text { Serpentine tube, with large diameter, thick wall and } \\
\text { large thermal resistance, adopts immersed cooling } \\
\text { section, which has large invalid heat exchange area } \\
\text { and large total heat exchange area }\end{array}$ \\
\hline Dimensions & $\begin{array}{l}\text { Compact layout, smaller shape, smaller heat } \\
\text { exchange area and lighter total weight of } \\
\text { equipment. }\end{array}$ & $\begin{array}{l}\text { The serpentine high-pressure heater adopts 3-4 } \\
\text { stroke, with larger shape, larger heat exchange area } \\
\text { and heavier total weight of equipment. }\end{array}$ \\
\hline Water side resistance & $\begin{array}{l}\text { It has water chamber, tube sheet, etc., and has } \\
\text { high resistance }\end{array}$ & Header distribution, low total resistance \\
\hline Steam side resistance & \multicolumn{2}{|c|}{ There is little difference between U-tube heater and serpentine tube heater } \\
\hline production cycle & \multicolumn{2}{|c|}{ Serpentine tube heater is longer than U-tube heater, subject to foreign suppliers } \\
\hline Initial investment & \multicolumn{2}{|c|}{ The height of serpentine tube is larger than that of U-tube } \\
\hline
\end{tabular}

As an important component of serpentine highpressure heater, serpentine heat exchange tube directly determines the stability and reliability of serpentine highpressure heater. It is a key process in the manufacturing of serpentine high-pressure heater and an important node to promote the localization of serpentine high-pressure heater. The diameter and length of serpentine heat exchange tube are larger and longer than those of conventional heater. The bending radius and angle of each layer are different, but the bending shape of each row of heat exchange tubes is the same[10]. At present, the domestic pipe material suppliers do not have the ability to provide serpentine heat exchange tubes. If the serpentine tubes are purchased in China, the suppliers must increase the investment in fixed assets, carry out relevant technology development and equipment development, and their preliminary quotation is obviously higher than the market price.Therefore, in order to ensure the processing cycle and quality of serpentine heat exchanger tube, and effectively control the cost, it is necessary to purchase straight tube and bend the serpentine heat exchange tube by itself.At the same time, because there is no relevant design standard for serpentine tube in China, the domestic serpentine heat exchanger adopts the general heat exchanger design, the wall thickness is much higher than that of foreign serpentine heat exchange tube, and the heat exchange efficiency is low, which also causes the increase of cost and the waste of resources. Therefore, it is necessary to study the design method of serpentine heat exchanger tube.

\section{Conclusions}

It could be seen that the ultra supercritical reheating is a high-end technology in the field of power equipment manufacturing, which represents the strength and design level of national major equipment manufacturing industry.Based on the development of key components technology of millions of secondary reheat units, solving the design and manufacturing problems of serpentine high-pressure heater, optimizing the heat exchange efficiency of serpentine high-pressure heater, and improving the operation reliability, will help to promote the development process of China's high-end power equipment, and provide important technical support for the quality supervision and management of serpentine high-pressure heater. 


\section{Acknowledgments}

This study has received funding by Scientific Research Projects of Shanghai Quality and Technical Supervision (2019-22), and Shanghai Science and Technology Talents Program (19XD1432600). The authors are grateful for the financial supports provided by Shanghai engineering research center of pressure pipeline intelligent inspection and National Heat Exchanger Product Quality Inspection Center.

\section{References}

1. Gu, Y. X., Wang, SP., Yang, SM., et al (2013) Thermal economic analysis of ultra supercritical secondary reheat generator set. Thermal Power Generation, 42 (9): 7-9.

2. Zhao, W. C.. (2017) Overall design and economic analysis of $1 \mathrm{MW}$ ultra supercritical secondary Reheat Unit. Science And Technology Wind, (21): 228-228.

3. Deng, C. G., Zheng J., Zou, L. M., et al. (2017) Feasibility analysis of serpentine tube high pressure heater used in $1000 \mathrm{MW}$ secondary Reheat Unit. Southern Energy Construction, 4 (1): 44-48.

4. Xu, H. B., Chen, Q. (2015) Design and economic analysis of 10 stage regenerative system with adjustable stage for $1000 \mathrm{MW}$ Ultra Supercritical Unit. China electric power, 48 (12): 74-78.

5. Lin, F. (2014) Application of serpentine tube high pressure heater in large thermal power unit. Power Station Auxiliary Equipment, 35 (3): 5-7.

6. Zhou, R.. (2007) Discussion on selection of high pressure heater for $1000 \mathrm{MW}$ Ultra Supercritical Unit. Heat Engine Technology, (1): 1-5.

7. Dongfang Electric Group Dongfang Boiler Co., Ltd., discussion draft for technical exchange of serpentine tube high pressure heater [R], Dongfang Electric Group, Shanghai, 2015.

8. China Energy Engineering Group Guangdong Electric Power Design and Research Institute Co., Ltd., special research report on configuration selection of high pressure heater for secondary Reheat Unit $[\mathrm{R}]$, China Energy Construction Group Guangdong Electric Power Design and Research Institute Co., Ltd., Guangzhou, 2015.

9. Li, Y. L., Liu, J. R. (2018) Study on the configuration of high pressure heater for $1 \mathrm{MW}$ secondary Reheat Unit. Shandong Electric Power Technology, 45 (2): 4.

10. Zhu, J. W. (2017) Structural characteristics and manufacturing process analysis of serpentine tube high pressure heater. Energy Research and Information, 33 (2): 92-95. 